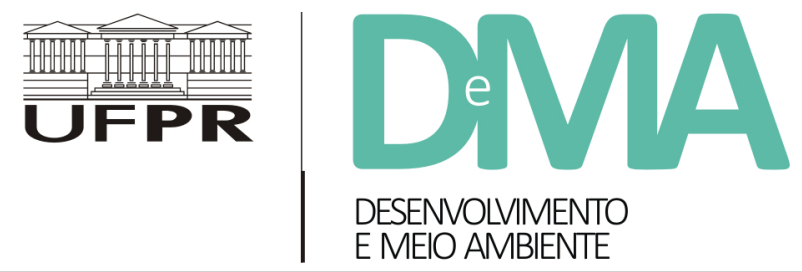

\title{
Base ecossistêmica da atividade pesqueira artesanal: estudo de caso no Baixo Estuário da Lagoa dos Patos (BELP), RS, Brasil
}

\section{Ecosystem Basis for Artisanal Fishing: Case Study in the Low Estuary of the Patos Lagoon (BELP), RS, Brazil}

\author{
Julliet Correa da COSTA ${ }^{1 *}$, Milton Lafourcade ASMUS ${ }^{1}$ \\ ${ }^{1}$ Universidade Federal do Rio Grande (FURG), Rio Grande, RS, Brasil. \\ *E-mail de contato: jullietcorrea@hotmail.com
}

Artigo recebido em 31 de agosto de 2017, versão final aceita em 12 de novembro de 2017.

RESUMO:
O presente trabalho caracterizou a base ecossistêmica que subsidia a atividade pesqueira artesanal no Baixo
Estuário da Lagoa dos Patos (BELP), RS, Brasil, utilizando a pesca da tainha (Mugil liza) como uma pescaria
representativa. Foram identificados 10 (dez) ecossistemas dominantes que dão suporte de diferentes maneiras
à atividade: Marismas; Vegetação Aquática Submersa; Baixios; Planos Intermareais; Zonas Intermediárias;
Praias Estuarinas; Canais de Drenagem; Canais; Molhes e Costeiro Adjacente. Na análise dos serviços gerados
por tais ecossistemas, de acordo com a sua classificação - suporte, provisão, regulação e cultural -, alguns
aparecem ligados de modo direto à pesca artesanal, principalmente os serviços de Suporte (Área de refúgio;
Berçário; Base para biodiversidade; Ciclagem de nutrientes; Espaço para pesca; Navegabilidade; Corredor
ecológico; Atracadouro para embarcações; Espaço para ocupação) e Provisão (Produção de biomassa; Fibras
vegetais). Para compreender os principais fluxos e processos percorridos pelos serviços ecossistêmicos e
suas inter-relações com os diferentes componentes ambientais e socioeconômicos da atividade pesqueira,
foram confeccionados dois modelos conceituais de fluxo energético. O primeiro para o BELP, para entender o
funcionamento geral do estuário e o conjunto de componentes e processos que estão conectados e subsidiam
o subsistema da pesca, e o segundo - com maior nível de detalhamento - para apresentar os diferentes
aspectos da atividade pesqueira e a produção (e geração) dos serviços ecossistêmicos que atuam diretamente
na manutenção da pesca artesanal da tainha nesta área. Tal análise torna possível e alavanca a base de
informações integradas deste sistema no estuário, considerando seus aspectos ecológicos, econômicos e
sociais. A expectativa é que os resultados produzidos se configurem como subsídios para uma gestão com base
ecossistêmica da pesca artesanal, levando em conta os diferentes usos e benefícios dos ecossistemas nesta


região. Da mesma forma, propõe um procedimento de análise com potencial de ser aplicado em ambientes estuarinos com atividades pesqueiras correspondentes.

Palavras-chave: base ecossistêmica; serviços ecossistêmicos; Baixo Estuário da Lagoa dos Patos; pesca artesanal.

ABSTRACT: The present work characterized the ecosystem base that subsidizes the artisanal fishing activity in the Low Estuary of Lagoa dos Patos (BELP, in Portuguese) utilizing the mullet fishery (Mugil liza) as a representative one. Ten (10) dominant ecosystems have been identified supporting the fish activity in different ways: Salt Marshes; Submerged Aquatic Vegetation; Shallow Waters; Intertidal Plans; Intermediate Zones; Estuarine Beaches; Drainage Canals; Canals; Jetties and Adjacent Marine Systems. In the analysis of the services generated by these ecosystems, according to their classification - support, provision, regulation and culture - some are directly linked to artisanal fishing, mainly Support services (Area of refuge, Nursery, Base for biodiversity, Nutrients Cycling; Space for fishing; Navigability; Ecological corridor; Boat Anchor sites; Space for occupation) and Provision (Production of biomass; Natural fibers). To understand the main flows and processes covered by ecosystem services and their interrelationships with the different environmental and socioeconomic components of the fishing activity, two conceptual energy models were made. The first one for the BELP, to understand the general functioning of the estuary and the set of components and processes that are connected and subsidize the fishing subsystem, and the second - with a greater level of detail - to present the different aspects of the fishing activity and the production (and generation) of the ecosystem services that directly act in the maintenance of the artisanal fishing of the mullet in this area. This analysis makes possible and promotes the integrated information base of the artisanal fishing system in the estuary, considering its ecological, economic and social aspects. It is expected that the produced results will serve as subsidies for an ecosystem-based management of artisanal fisheries, taking into account the different uses and benefits of the ecosystems in the BELP. In the same way, it proposes a procedure analysis with the potential to be applied in estuarine environments with corresponding fishing activities.

Keywords: ecosystemic basis; ecosystem services; Low Estuary of Lagoa dos Patos; artisanal fishing.

\section{Introdução}

A pesca artesanal - ou de pequena escala - é uma prática tradicional muito importante para os habitantes das regiões costeiras, especialmente nos países em desenvolvimento, onde a atividade gera uma considerável fonte de alimentação e renda para uma grande parcela da sociedade (Castello, 2010; FAO, 2012). No contexto global, o setor emprega mais de $90 \%$ de um total estimado em 39 milhões de pescadores e possui grande importância na dieta proteica humana, possibilitando a segurança alimentar de aproximadamente 357 milhões de pessoas (FAO, 2014). Ao mesmo tempo, sua sustentabilidade ecológica e socioeconômica encontra-se ameaçada, principalmente devido à extração acelerada dos recursos pesqueiros e ao estado vigente de degradação dos habitats marinhos e costeiros (entre outros problemas ambientais), o que ocasiona graves impactos negativos - em diferentes escalas de espaço e tempo - que afetam não só as espécies, mas também o funcionamento dos ecossistemas e a sua capacidade de fornecer bens e serviços essenciais para a humanidade (Worm et al., 2006; Halpern et al., 2008). A pesca industrial - ou comercial de larga escala - tem sido apontada como a principal 
responsável pelo uso desordenado dos estoques pesqueiros e pelos inúmeros danos gerados na estrutura e na função dos ecossistemas (Agardy, 2000; Kaiser et al., 2003; Worm et al., 2006; Halpern et al., 2008). Por outro lado, as pescarias artesanais (em determinadas áreas) também provocam diversos impactos ambientais, relacionados principalmente ao excesso da capacidade pesqueira, ao uso de artes de pesca não declaradas e não seletivas e à ocorrência de práticas ilegais e desordenadas (Misund et al., 2002; Berkes, 2006; Kolding et al., 2014). No entanto, a pesca artesanal apresenta-se como uma modalidade mais sustentável - quando comparada em termos de eficiência energética com a atividade industrial -, pois utiliza artes de captura de pequeno porte (o que reduz os danos físicos aos ecossistemas), consome menos combustível (desembarca mais peixes por unidade de volume de combustível utilizado) e por consequência apresenta menores descartes (Bycath), devido à diversidade de modos de pesca e estratégias de subsistência (Béné et al., 2010; Kolding et al., 2014).

Em todo o mundo, a gestão da atividade pesqueira (independente de sua modalidade) se desenvolveu e se estabeleceu tendo como foco principal a gestão do recurso pesqueiro, concentrando-se, sobretudo na obtenção do rendimento máximo sustentável por meio de uma visão top-down (Pikitch et al., 2004). No Brasil não foi diferente. Até o final do século XX, a gestão pesqueira foi impulsionada por uma variedade de políticas governamentais fragmentadas e setorizadas, voltadas prioritariamente para a expansão da captura, da modernização e do desenvolvimento da pesca industrial (Abdallah \& Sumaila, 2007). A pesca artesanal nunca foi o objeto principal das preocupações do governo brasileiro. O setor permaneceu marginalizado po- liticamente até meados da década de 1980, quando o Sistema Nacional de Crédito Rural (criado em 1965) passou a auxiliar financeiramente também os pescadores artesanais (Hellebrandt, 2012). Nas décadas seguintes, as medidas dirigidas à categoria, apesar de representarem diversas melhorias, foram insuficientes para fortalecê-la e reverter a vulnerabilidade socioambiental das comunidades pesqueiras (Azevedo \& Pierri, 2014). A falta de atenção política é diretamente responsável pela escassez de investimentos em pesquisa e pela carência de informações básicas sobre as condições técnicas, socioeconômicas e ambientais dos sistemas de pesca artesanal, dificultando, assim, a identificação e a avaliação de medidas de gestão necessárias para a sustentabilidade dos recursos e para a proteção da atividade como meio de vida (Kalikoski \& Vasconcellos, 2013). Nesta conjuntura, e com recursos financeiros limitados, torna-se muito importante desenvolver e aplicar uma avaliação rápida, que proporcione uma base para diagnosticar o estado da pesca de pequena escala na zona costeira brasileira.

A necessidade de analisar a atividade pesqueira artesanal sob um enfoque mais amplo e integrado, abordando seus aspectos ecológicos, econômicos, sociais e políticos, é uma tendência mundial de gestão e manejo deste setor, o que deixa de lado os estudos com enfoque puramente biológico e os substitui por um enfoque ecossistêmico que considera não apenas as espécies exploradas, mas também os ecossistemas que lhes dão suporte (componentes ecológicos, econômicos e sociais) e o próprio ser humano (Pikitch et al., 2004; Berkes, 2006; Link, 2010; Link \& Browman, 2014; FAO, 2015). Nesta perspectiva, abandona-se a ideia de uma gestão voltada à preservação individual das espécies e parte-se para uma abordagem que 
objetiva fazer a manutenção dos ecossistemas em que a atividade pesqueira está inserida, com ênfase nos seus aspectos ambientais e socioeconômicos. Dentre os modelos estabelecidos, a Gestão com base ecossistêmica - tradução livre do inglês Ecosystem-based management (EBM) - tem como objetivo geral a manutenção dos recursos naturais de uma forma holística, reconhecendo as conexões entre os diferentes elementos dos ecossistemas - incluindo os seres humanos (Leslie \& McLeod, 2007; Leslie \& Kinzig, 2009) - e os processos responsáveis por produzir os serviços ecossistêmicos e proporcionar benefícios sociais (Arkema et al., 2006).

A pesca artesanal é uma atividade essencial, mas não única nem independente das outras que interagem e competem pelos múltiplos serviços e benefícios gerados pelos ecossistemas costeiros. Para entendê-la em um contexto de ecossistemas (enfoque ecossistêmico), é preciso primeiramente identificar sua base ecossistêmica (ecológica, socioeconômica e institucional) e compreender os diferentes processos e mecanismos que permitem a geração e o funcionamento dos serviços nos ecossistemas em que ela ocorre ou utiliza. A integração dos serviços ecossistêmicos é um dos pilares básicos para a gestão pesqueira com base ecossistêmica, pois eles refletem diretamente os valores e benefícios que a atividade (e a sociedade) obtém destes ambientes (Santos-Martín et al., 2015), o que pode contribuir para a eficiência nas estratégias de gestão, à medida que a diversidade de interações humano-naturais (negativas e positivas) passa a ser mais bem compreendida e os benefícios (e os riscos de perdas) começam a ser gerenciados.

No sul do Brasil, ao longo da desembocadura do estuário da Lagoa dos Patos e da zona costeira adjacente, localiza-se um dos principais polos pesqueiros - estuarino e marinho - desta região, margeado pelas cidades de Rio Grande e São José do Norte $^{1}$. A área se caracteriza pela grande produção e pela alta diversidade biológica e também é um local muito importante para criação, reprodução e alimentação dos principais recursos pesqueiros explorados comercialmente pela pesca local de pequena escala (Kalikoski \& Vasconcellos, 2013). Nos últimos 30 anos, o sistema de pesca artesanal do Baixo Estuário da Lagoa dos Patos (BELP) entrou em colapso, sobretudo devido ao abrupto declínio dos estoques pesqueiros, o que gerou reflexos deletérios nos macroelementos sociais, econômicos e ecológicos da atividade (Kalikoski et al., 2006). Além da sobrepesca, os recursos são diretamente afetados por outros impactos relacionados à contaminação das águas e sedimentos por resíduos e efluentes; às operações de dragagem; à perda de habitats de berçário nas margens estuarinas, como marismas e enseadas rasas vegetadas que vêm sendo rapidamente modificadas pela expansão imobiliária e industrial e/ou pela criação de aterros sanitários e depósitos de lixo (Freitas \& Tagliani, 2009; Tagliani \& Asmus, 2011). Ademais, as espécies pesqueiras também são diretamente afetadas pelas intensas condições climáticas (regime de chuvas) e hidrológicas locais (variação de salinidade e nível da água) (Vieira et al., 2008).

\footnotetext{
${ }^{1}$ Nesta pesquisa, esta porção de água é referida como Baixo Estuário da Lagoa dos Patos (BELP). O baixo estuário é delimitado ao norte pela latitude que passa pela Ilha de Torotama em direção ao Saco do Medanha e ao sul pela foz do próprio estuário da Lagoa dos Patos (Enquadramento dos Recursos Hídricos da Parte Sul do Estuário da Laguna dos Patos [Resolução CONAMA 20/862]).
} 
Atualmente, a tainha (Mugil liza) é considerada o segundo recurso pesqueiro em importância econômica para os pescadores artesanais do estuário da Lagoa dos Patos, perdendo apenas para o camarão-rosa (Farfantepenaeus paulensis) (Kalikoski \& Vasconcellos, 2013; MPA/MMA, 2015; Julliet, obs. pessoal). Sua captura ocorre o ano todo no estuário e nas águas costeiras adjacentes e, quando a temporada de pesca do camarão fracassa, passa a ser o recurso mais importante para a economia local. A espécie está sobre-explotada, segundo o Ministério do Meio Ambiente (MMA), desde 2004 e possui um plano de manejo para uma exploração sustentável (MPA/MMA 2015). O controle da pesca artesanal no BELP é feito por meio de políticas governamentais tradicionais que regulam principalmente a retirada do estoque, operando por meio da legislação vigente e da fiscalização pelas instituições responsáveis (MMA, MAPA, MDIC IBAMA, Fórum da Lagoa dos Patos).

Até o presente momento, existe ampla bibliografia disponível e constante produção de conhecimento técnico e científico acerca de todos os componentes (biológicos, ecológicos, sociais e econômicos) e processos da pesca artesanal da espécie tainha (Mugil liza) e dos ecossistemas desta região, porém, estas informações ainda não se apresentam de forma sistematizada para o uso em iniciativas de gestão integrada. Nesta perspectiva, sugere-se o enfoque ecossistêmico como uma abordagem capaz de viabilizar uma gestão adequada da pesca artesanal da tainha no BELP. Todavia, antes é preciso estabelecer uma base de informações sobre a atividade pesqueira e sobre os ecossistemas (e seus diferentes aspectos) de maneira integrada.

Portanto, este trabalho buscou caracterizar a base ecossistêmica da atividade pesqueira artesanal no Baixo Estuário da Lagoa dos Patos, utilizando a pesca da tainha (Mugil liza) como um caso representativo, identificando os componentes ecológicos e socioeconômicos, as relações e os serviços ecossistêmicos que subsidiam a pesca e os possíveis impactos (positivos e/ou negativos) gerados pela degradação (ou perda) dos ecossistemas e seus serviços.

\section{1. Área de estudo e características}

A Lagoa dos Patos está localizada na região sul do Brasil, entre $30^{\circ}$ e $32^{\circ} \mathrm{S}$ de latitude e $50^{\circ}$ e $52^{\circ} \mathrm{W}$ de longitude, e é considerada um dos mais importantes recursos hídricos do país. Em seu limite sul, apresenta um ecossistema estuarino de aproximadamente $1.000 \mathrm{~km}^{2}$ de área, o que representa $10 \%$ da superfície total da laguna (Seeliger $\&$ Costa, 2010). Ao longo de sua desembocadura e da zona costeira adjacente, entre os municípios de Rio Grande e São José do Norte, localiza-se o Baixo Estuário da Lagoa dos Patos (BELP) (Figura 1).

Devido a sua localização na interface terra-mar, o BELP abriga uma diversidade de ecossistemas naturais de elevada importância ecológica e socioeconômica. O domínio aquático é caracterizado pela presença de dois ambientes principais ecologicamente distintos: as baías (ou enseadas) rasas e protegidas e o corpo de água central aberto e profundo (Asmus, 1998). As margens do corpo estuarino e das ilhas (ilhas dos Marinheiros, da Torotama, das Pombas, da Pólvora, dos Cavalos e outras) são constituídas por planos intermareais lamosos e praias arenosas (Asmus et al., 2015); recobertas por marismas (Marangoni \& Costa, 2010) e prados de vegetação aquática submersa (VAS) 
(Copertino et al., 2016), entre outros ambientes que geram inúmeros serviços ecossistêmicos e garantem benefícios significativos para os habitantes desta região, o que viabiliza a concentração de muitas atividades socioeconômicas em seu entorno. A economia local é mantida por estas atividades - muitas delas conflitantes entre si-, como agricultura, pesca artesanal (camarão e peixes), turismo, aquicultura,

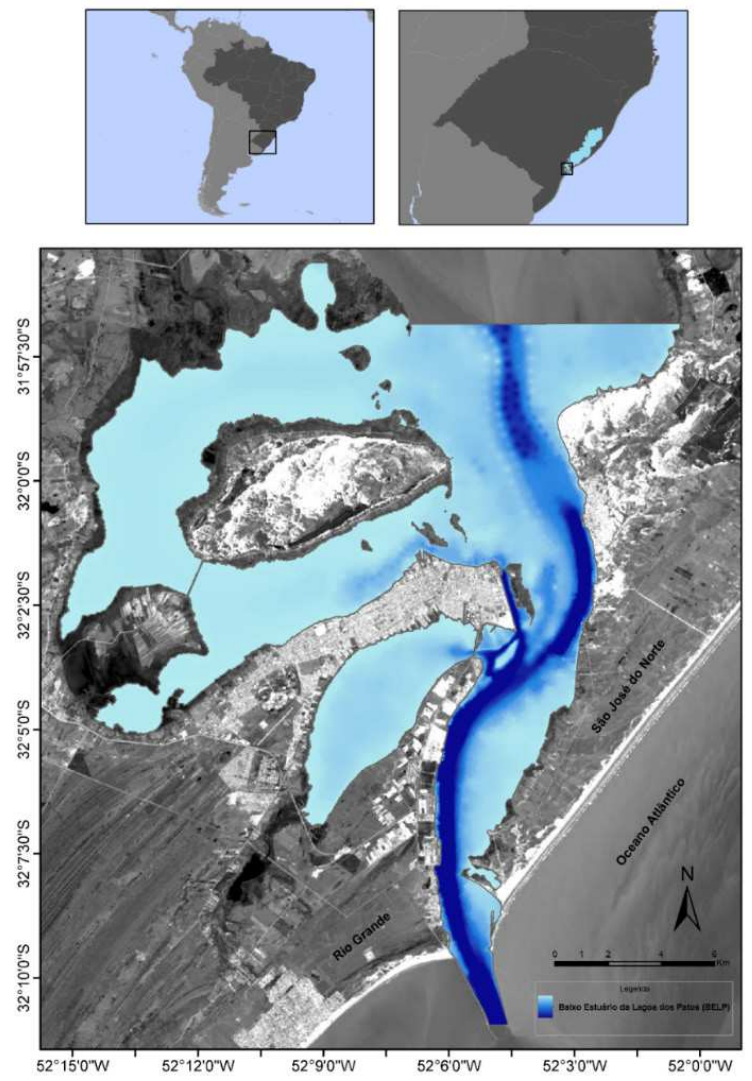

FIGURA 1 - Baixo Estuário da Lagoa dos Patos (BELP) - em destaque batimetria do canal de acesso - Sistema de Coordenadas Geográficas, Datum WGS84.

FONTE: Elaborada pelos autores. operações portuárias e industriais (com significativo potencial de poluição derivado das indústrias de fertilizantes, de processamento de pescado e da refinaria de petróleo ali situadas) (Freitas \& Tagliani, 2009; Tagliani \& Asmus, 2011). Recentemente, os municípios passaram por um ciclo de crescimento econômico impulsionado pela indústria naval, com a instalação de dois grandes estaleiros para a construção de plataformas para exploração de petróleo. Estes empreendimentos, inicialmente, apresentaram perspectivas de expansão para a economia local, porém, também trouxeram impactos ambientais significativos sobre os ecossistemas estuarinos e seus serviços.

Em consequência da falta de planejamento e de gestão durante o processo de expansão urbana, agrícola e industrial, muitos ecossistemas das margens do estuário encontram-se degradadas (Tagliani \& Asmus, 2011). As ocupações, moradias e zona industrial-portuária conflitam (em diferentes escalas) com a presença de áreas de preservação permanente, como a vegetação de marismas e as enseadas rasas, que são habitats muito importantes para a manutenção da pesca artesanal nesta região (Freitas \& Tagliani, 2009). A atividade ocorre em todo o domínio aquático do BELP e origina territórios populacionais nas margens, conhecidos como comunidades pesqueiras. Os pescadores trabalham regularmente nas áreas próximas as suas comunidades, o que não demanda tempo de navegação e garante economia de combustível e de tempo (Schafer \& Reis, 2008).

O canal de acesso ao BELP - Canal do Rio Grande - é fixado por dois molhes que conectam o ambiente estuarino ao Oceano Atlântico adjacente e é responsável pela troca de nutrientes e sedimentos entre estes ecossistemas. Os processos que contro- 
lam a mudança de água nesta zona (precipitação e ventos predominantes NE-SW) também são responsáveis pelo transporte e pela distribuição de larvas de peixes, crustáceos, moluscos, fitoplâncton e zooplâncton para o estuário, onde eles podem aproveitar a proteção e os recursos alimentares das zonas rasas para seu desenvolvimento (Garcia et al., 2001). Este canal possui dimensões aproximadas de $18 \mathrm{~km}$ de extensão e varia entre 0,5 a $3 \mathrm{~km}$ de largura, funcionando também como um escoadouro natural de toda a bacia de drenagem do sistema Lagoa dos Patos-Lagoa Mirim, ambas interligadas na zona costeira do Rio Grande do Sul (Barbosa et al., 2012).

\section{Metodologia}

A pesquisa teve uma ampla revisão bibliográfica, realizada em todas as fases de seu desenvolvimento, como forma de garantir o aporte teórico atualizado dos assuntos tratados. Isto permitiu apresentar os conceitos e definições que orientaram o escopo da investigação, seu planejamento, subsídios e coleta de dados, além da melhor interpretação dos seus resultados. A seguir, a metodologia é detalha$\mathrm{da}$, descrevendo os procedimentos e a forma como foram utilizados.

\subsection{Caracterização da atividade pesqueira artesanal no Baixo Estuário da Lagoa dos Patos (BELP). Estudo de caso: Pesca artesanal da tainha (Mugil liza)}

A descrição e a caracterização da atividade pesqueira artesanal e da pesca da tainha (Mugil liza) na área de estudo foram feitas por meio de levanta- mento bibliográfico e do uso de dados secundários compilados. Particularmente, foram observados os trabalhos de Lemos et al. (2014); Kalikoski \& Vasconcellos (2013); Abdallah \& Sumaila (2007); Ferreira (2007); Haimovici et al. (2006); Garcez \& Sanchez-Botero (2005); e Reis \& D’Incao (2000).

\subsection{Identificação e caracterização}

dos ecossistemas dominantes, serviços ecossistêmicos, beneficios e atores sociais relacionados à pesca artesanal no Baixo Estuário da Lagoa dos Patos (BELP)

Para esta análise, foi utilizada como referência principal a Matriz de Ecossistemas e Serviços Ecossistêmicos proposta por Asmus et al. (2015) e Scherer \& Asmus (2016). A metodologia utilizada para a construção desta matriz é frequentemente aplicada para preencher lacunas em pesquisas científicas, sendo denominada por diferentes autores como "conhecimento especializado" (Krueger et al., 2012; Nordlund et al., 2016). Neste estudo, constituiu-se na realização de uma série de eventos (oficinas, reuniões e saídas de campo) nos quais foram obtidas opiniões e informações de diversos especialistas sobre os principais ecossistemas (das margens e do domínio aquático do BELP) e o suporte que fornecem aos diferentes aspectos da atividade de pesca artesanal, os serviços ecossistêmicos prestados por eles (classificados por tipo de serviço), seus principais usos e/ou benefícios socioeconômicos e os atores sociais diretamente beneficiados. Este conhecimento foi obtido por meio de entrevistas com base em roteiros semiestruturados com perguntas abertas, o que caracteriza a pesquisa social qualitativa (Minayo, 2001) e representado de 
maneira sistemática em uma nova matriz para que possa ser compreendido e difundido pelos distintos usuários deste sistema e, assim, oferecer respostas para as questões relacionadas à base de informação da atividade pesqueira artesanal, possibilitando que, posteriormente, informações científicas e/ou tradicionais complementares possam ser adicionadas ao conjunto de dados. Utilizou-se a definição de especialista proposta por Krueger et al. (2012): "Um perito pode ser qualquer pessoa com experiência relevante (ou em profundidade) em relação a um tópico de interesse". A partir deste critério, definiram-se como especialistas os profissionais, investigadores (e professores) e também os atores sociais que trabalham com conteúdos relacionados ao ambiente natural e/ou social do BELP e/ou com assuntos relevantes para os ecossistemas identificados. Nesta etapa, também foram explorados dados de revisão bibliográfica, onde informações físicas, ambientais e socioeconômicas dos ecossistemas foram compiladas e analisadas. Os serviços ecossistêmicos foram classificados segundo proposta sugerida por de De Groot et al. (2002), observando a classificação sugerida pela Avaliação Ecossistêmica do Milênio (MEA, 2005). As classes adotadas foram Serviços de Suporte, Regulação, Provisão e Culturais.

\subsubsection{Mapas de distribuição geoespacial da base ecossistêmica da pesca artesanal no BELP}

Para oferecer uma ideia de cobertura de cada ecossistema identificado, foram confeccionados mapas de distribuição geoespacial dos ecossistemas das margens e do espaço aquático (em relação à profundidade do BELP), utilizando uma série de ferramentas do software ArcMap 10.3®. Os diferentes produtos foram elaborados a partir de dados secundários adaptados do estudo de Nyland (2015). Na presente pesquisa, alguns arquivos foram editados, de acordo com os conceitos da literatura científica utilizada. A escala utilizada para vetorização e confecção dos mapas foi de 1:25000. O domínio aquático foi representado por um arquivo da batimetria multifeixe do BELP, cedido pelo Porto do Rio Grande $(2015)^{2}$. Este arquivo foi apresentado na forma contínua, por um Raster (arquivo matricial) - criado com o uso do interpolador IDW do ArcMap 10.3 -, onde foram geradas isolinhas de contorno e a partir delas extraídos e classificados os ecossistemas, as zonas intermediárias, os baixios e os canais.

O ecossistema Vegetação Aquática Submersa (VAS) foi obtido por uma imagem de Clorofila (mg/ $\mathrm{m}^{3}$ ) do satélite MODIS/Aqua do site Ocean Color da NASA. Esta imagem foi pré-processada no software Envi 5.0®, reprojetada (do HN para HS), ajustada e depois convertida para o formato vetorial com o uso de ferramentas do software ArcMap 10.3.

\subsection{Elaboração de modelos conceituais de fluxos energéticos}

Dois diagramas de fluxo de energia e materiais - SISTEMA BELP e SISTEMA DA PESCA - foram produzidos, visando ao entendimento dos fluxos (ou processos) percorridos pelos serviços

\footnotetext{
${ }^{2}$ Fonte: Instituto de Educação, Ciência e Tecnologia do Rio Grande do Sul, IFRS - Rio Grande, Curso Técnico Subsequente em Geoprocessamento.
} 
ecossistêmicos e suas inter-relações com os ecossistemas e com os componentes ambientais e socioeconômicos da atividade pesqueira artesanal da tainha no Baixo Estuário da Lagoa dos Patos. Para representar e analisar os diferentes modelos, foi utilizada a linguagem energética de Odum (1988), cuja abordagem ecológica, baseada nas leis da termodinâmica, possibilita definir os limites de cada sistema, identificar seus principais componentes de entrada e saída, os processos ecológicos, sociais e econômicos, as suas interações mais importantes e, por fim, o desenho do diagrama ou a sua arquitetura.

A estrutura dos modelos nos permite observar e compreender o sistema em seu princípio básico de organização, onde há um grande número de processos simultâneos. Fluxos mais simples e controles naturais tradicionalmente se localizam à esquerda, enquanto que os mais complexos e com controles socioeconômicos são normalmente representados à direita do diagrama. Uma descrição mais detalhada de cada símbolo e de seu equivalente matemático pode ser encontrada em vários trabalhos de Odum $(1972 ; 1983 ; 1988)$.

A construção dos diagramas se deu de forma interativa, nos quais a maioria das informações descritas deriva das seções anteriores deste trabalho e está baseada na literatura científica disponível. Após o desenho de repetidas versões, foram definidos os modelos finais para o Baixo Estuário da Lagoa dos Patos (SISTEMA BELP) e para a atividade de Pesca Artesanal da tainha (SISTEMA PESCA). Tais figuras foram confeccionadas utilizando uma série de ferramentas dos softwares Power Point e Adobe Photoshop.

\section{Resultados e discussões}

\subsection{Caracterização da atividade pesqueira artesanal no Baixo Estuário da Lagoa dos Patos (BELP). Estudo de caso: Pesca artesanal da tainha (Mugil liza)}

A pesca artesanal é uma prática tradicional que garante alimentação e renda para uma grande parcela das comunidades no entorno do Baixo Estuário da Lagoa dos Patos (BELP). No contexto local, Rio Grande e São José do Norte, de acordo com o censo organizado por Kalikoski \& Vasconcellos (2013), concentram juntas aproximadamente $70 \%$ dos pescadores artesanais - de um total de 3.259 entrevistados ${ }^{3}$ - das 153 localidades pesqueiras (nove municípios) que margeiam todo o estuário, o que evidencia a importância socioeconômica da pesca para este território. A atividade caracteriza-se pelo uso de pequenas embarcações, chamadas "botes", que variam entre 5 e 12 metros de comprimento. De modo geral, os botes menores que $8 \mathrm{~m}$ possuem baixa autonomia de navegação e não apresentam cobertura no convés (Haimovici et al., 2006; Kalikoski \& Vasconcellos, 2013). Os pescadores, normalmente, são os proprietários dos barcos e trabalham junto com seus familiares. É

\footnotetext{
${ }^{3}$ Este número passa para 4.089 se forem somados os familiares com alguma atividade de pós-captura (processamento, comércio, manutenção dos equipamentos). O número de recenseados está abaixo das estimativas das agências governamentais, colônias e sindicatos, que variam entre 7.500 e 15.335 pescadores, e abaixo dos mais de 8.000 beneficiados do seguro-desemprego na região. Estas discrepâncias são resultado de problemas no cadastramento feito pelas organizações de classe, da consideração ou não de pescadores ocasionais e da ineficácia dos sistemas de cadastro e documentação pelas instituições governamentais (Kalikoski \& Vasconcellos, 2013).
} 
comum atuar mais de um pescador numa mesma embarcação, sendo geralmente o dono, um ou mais proeiros (que recebem parte do lucro), e, dependendo da operação, podem embarcar até 5 pessoas em um mesmo bote (Julliet, obs. pess.). Os modos de vida dos pescadores artesanais são diversos e não dependem exclusivamente das atividades de captura. A unidade familiar pesqueira ${ }^{4}$ também atua (em intensidade variável) noutras tarefas importantes do processo de produção, como no beneficiamento do pescado e na manutenção dos equipamentos de pesca (Pasquotto, 2005). Regularmente, os pescadores acabam buscando também outras fontes de renda além da pesca como estratégia de sustento, incluindo atividades que tenham ou não relação com o setor. As opções apontadas com mais frequência são: pescar o ano todo, inclusive espécies alternativas como o siri azul (Callinectes sapidus), receber o seguro-desemprego, trabalhar na manutenção dos equipamentos de pesca e em serviços ocasionais, como, por exemplo, na construção civil (Kalikoski \& Vasconcellos, 2013).

No contexto da pesca artesanal da tainha (Mugil liza ${ }^{5}$ ), a captura ocorre ao longo de todo o ano, seguindo o padrão de uso dos habitats pela espécie nos diferentes estágios do seu ciclo de vida (Lemos et al., 2014), sendo realizada predominantemente com duas artes de pesca: com o uso de redes de emalhe fixo e de redes de cerco (lance) (Ferreira, 2007). A comercialização da produção se dá de maneiras distintas. Geralmente, o pescado é repassado para intermediários e atravessadores e eventualmente a venda é realizada diretamente ao consumidor (Kalikoski \& Vasconcellos, 2013). O controle é feito pelas políticas governamentais que regulam a retirada do estoque, operando por meio da legislação vigente e da fiscalização pelas instituições responsáveis (MMA, IBAMA, Fórum da Lagoa dos Patos).

A tainha (Mugil liza) é considerada ameaçada de sobrepesca, devido à elevada intensidade das frotas de pesca industrial e artesanal que atuam sobre este recurso na região sul do Brasil (Vasconcellos et al., 2007, MPA/MMA, 2015). A variabilidade nas capturas demonstra que a espécie também é dependente das condições ambientais. Vieira et al. (2008) observaram os efeitos negativos da elevada precipitação associada a eventos de El Niño durante suas safras no estuário da Lagoa dos Patos. Estes fenômenos reduzem o recrutamento dos juvenis para o estuário e afetam sua migração reprodutiva para o ambiente marinho adjacente. Como resultado, existe uma relação inversa entre a pluviosidade (e a consequente vazão do estuário) e as capturas de tainha nesta região. Atualmente, a espécie é o segundo recurso pesqueiro em importância econômica para os pescadores artesanais do estuário da Lagoa dos Patos, atrás apenas do camarão (Farfantepenaeus paulensis) (Kalikoski \& Vasconcellos, 2013; MPA/ MMA, 2015; Julliet, obs. pessoal). Em algumas comunidades (principalmente aquelas localizadas nas áreas mais interiores do estuário), a tainha tornou-se a mais importante, seguida pela corvina (Micropogonias furnieri), como é o caso da Colônia

\footnotetext{
${ }^{4}$ Família, grupos de vizinhança ou parentesco (Pasquotto, 2005).
}

${ }^{5} \mathrm{O}$ Estuário da Lagoa dos Patos $\left(32^{\circ} \mathrm{S}\right)$ representa o principal local de berçário para o estoque sul de Mugil liza - que se distribui da costa da Argentina até o litoral de São Paulo -, pois tem a maior abundância de juvenis no período de recrutamento e também ao longo de todo ano (quando comparado com outros estuários da região sul do Brasil) (Lemos et al., 2014). 
Z3 (Pelotas) (Hellebrandt, 2012). Dados complementares da produção pesqueira do estuário da Lagoa dos Patos podem ser conferidos nos boletins do Projeto Estatísticas de Desembarque Pesqueiro RS (MPA/FURG, 2010). As últimas informações disponibilizadas para os anos 2013-1, 2013-2, 2014, 2015 e 2016 apresentaram alguns dados importantes para esta pesquisa.

\subsection{Identificação e caracterização dos ecossistemas dominantes, serviços ecossistêmicos, benefícios e atores sociais relacionados à pesca artesanal no BELP}

De acordo com a categorização proposta por Asmus et al. (2015), foram identificados 10 (dez) ecossistemas dominantes que dão suporte aos diferentes aspectos da atividade de pesca artesanal no Baixo Estuário da Lagoa dos Patos (BELP): Marismas; Vegetação Aquática Submersa; Baixios; Planos Intermareais; Zonas Intermediárias; Praias Estuarinas; Canais de Drenagem; Canais; Molhes; Costeiro Adjacente.

Os ecossistemas foram caracterizados de forma não necessariamente homogênea, considerando a disponibilidade e a quantidade de informações encontradas na literatura científica sobre cada um deles, suas características e os serviços ecossistêmicos que fornecem. Alguns destes ambientes já foram discutidos em muitos estudos (ecológicos, físicos, socioeconômicos etc.) desenvolvidos na área de estudo e outros estão sendo caracterizados pela primeira vez de forma sistêmica nesta pesquisa.
Os Canais de Drenagem e os Molhes, por exemplo, são ecossistemas antropizados (construídos pelo homem) e influenciam diretamente nos fluxos e processos que ocorrem nos ecossistemas naturais, podendo alterar e/ou modificar a sua capacidade de produção.

Na análise dos serviços ecossistêmicos - processos gerados pelos ecossistemas que proporcionam alguma forma de benefício -, todos eles estão ligados de modo direto à pesca artesanal no BELP, de acordo com a sua classificação - suporte, provisão, regulação e cultural. O serviço de suporte é o que apresenta maior destaque, visto que ocorre em todos os ecossistemas.

Os serviços ecossistêmicos identificados foram: Suporte: Área de refúgio; Berçário, Base para biodiversidade, Ciclagem de nutrientes, Espaço para pesca, Navegabilidade, Corredor ecológico, Atracadouro para embarcações, Espaço para ocupação; Provisão: Produção de biomassa, Fibras vegetais; Regulação: Diluição, Balanço hidrológico, Estabiliza navegação; Culturais: Cenário, Relações sociais, Reprodução cultural, Valor contemplativo.

A confecção de uma matriz para a pesca artesanal permite entender a conexão direta da atividade com os ecossistemas no BELP, o uso que este setor faz destes ambientes e a maneira como utiliza os serviços ecossistêmicos em favor do seu bem-estar (benefícios e atores beneficiários ${ }^{6}$ ). $\mathrm{Na}$ Tabela 1, é possível analisar um extrato da matriz, como exemplo. Alguns dos ecossistemas geoespacializados podem ser visualizados por meio dos mapas de distribuição espacial na Figura 2.

\footnotetext{
${ }^{6}$ Os pescadores artesanais foram considerados os atores sociais beneficiados pela pesca artesanal. É importante que existam estudos futuros, onde outros atores da cadeia produtiva pesqueira (atravessadores, consumidores, beneficiadores, etc.) possam ser designados em relação ao uso dos benefícios identificados.
} 
TABELA 1 - Matriz de ecossistemas, serviços, benefícios e atores beneficiados diretamente pela pesca artesanal no BELP.

\begin{tabular}{|c|c|c|c|c|}
\hline \multicolumn{5}{|c|}{ Base Ecossistêmica da Pesca Artesanal no Baixo Estuário da Lagoa dos Patos - BELP } \\
\hline Ecossistemas & Classificação & Serviços Ecossistêmicos & Usos / benefícios & Atores sociais beneficiados \\
\hline \multirow{4}{*}{ Marismas } & Suporte & $\begin{array}{c}\text { Área de refúgio / berçário / base } \\
\text { para biodiversidade / ciclagem de } \\
\text { nutrientes }\end{array}$ & Pesca artesanal & Pescador artesanal \\
\hline & Provisão & $\begin{array}{c}\text { Produção de biomassa / fibras } \\
\text { vegetais }\end{array}$ & $\begin{array}{c}\text { Pesca artesanal / atividade } \\
\text { artesanal / cobertura (constru- } \\
\text { ção, solo) }\end{array}$ & $\begin{array}{l}\text { Pescador artesanal / co- } \\
\text { munidade local / pequeno } \\
\text { agricultor }\end{array}$ \\
\hline & Regulação & $\begin{array}{l}\text { Filtragem sed. e nutri. / controle de } \\
\text { inundação / controle da erosão }\end{array}$ & $\begin{array}{l}\text { Qualidade da água / segurança } \\
\text { para ocupação adjacente }\end{array}$ & Comunidade local \\
\hline & Cultural & Cenário & $\begin{array}{l}\text { Valor contemplativo / lazer / ed. } \\
\text { ambiental }\end{array}$ & $\begin{array}{l}\text { Comunidade local / turista / } \\
\text { inst. ensino, ONGs }\end{array}$ \\
\hline \multirow{4}{*}{$\begin{array}{c}\text { Planos } \\
\text { Intermareais }\end{array}$} & Suporte & $\begin{array}{c}\text { Base para biodiversidade / ciclagem } \\
\text { de nutrientes } \\
\text { estrutura de suporte/ atracadouro para } \\
\text { embarcações }\end{array}$ & $\begin{array}{l}\text { Pesca artesanal / ocupação e } \\
\text { construção (baixa renda) }\end{array}$ & $\begin{array}{l}\text { Pescador artesanal / comuni- } \\
\text { dade local }\end{array}$ \\
\hline & Provisão & Produção de biomassa & Pesca artesanal & Pescador artesanal \\
\hline & Regulação & Balanço hídrico / diluição & $\begin{array}{c}\text { Cont. de alagamentos / receptor } \\
\text { de efluentes }\end{array}$ & $\begin{array}{l}\text { Comunidade local / Com- } \\
\text { panhia Rio-grandense de } \\
\text { Saneamento (CORSAN) }\end{array}$ \\
\hline & Cultural & Relações sociais / cenário & Lazer / educ. ambiental & Comunidade local \\
\hline
\end{tabular}

\begin{tabular}{|c|c|c|c|}
\hline Suporte & $\begin{array}{c}\text { Área de refúgio / berçário / espaço } \\
\text { para pesca / base para biodiversidade } \\
\text { / ciclagem de nutrientes / atracadouro } \\
\text { para embarcações }\end{array}$ & Pesca artesanal / diluição & $\begin{array}{l}\text { Pescador artesanal / comuni- } \\
\text { dade local }\end{array}$ \\
\hline
\end{tabular}

\section{Baixios}

\begin{tabular}{cccc} 
Provisão & Produção de biomassa & Pesca artesanal & Pescador artesanal \\
Regulação & Balanço hídrico & & \\
Cultural & Cenário / reprodução cultural & $\begin{array}{c}\text { Lazer / turismo / educ. ambien- } \\
\text { tal / pesca artesanal }\end{array}$ & $\begin{array}{c}\text { Comunidade local / pescador } \\
\text { artesanal / turista }\end{array}$ \\
\hline
\end{tabular}



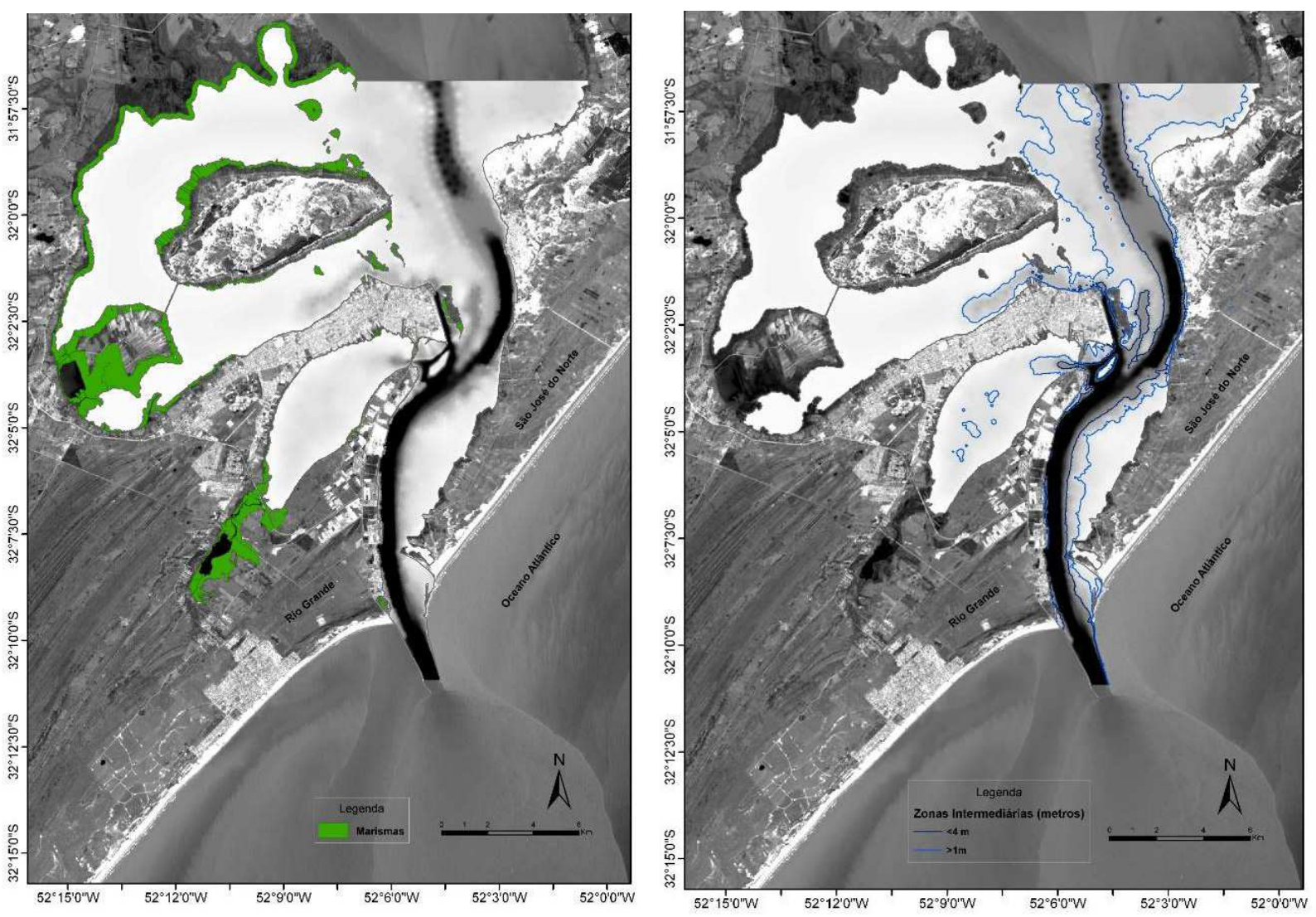

FIGURA 2 - Distribuição espacial dos ecossistemas Marisma e Zona Intermediária no Baixo Estuário da Lagoa dos Patos (BELP) - Sistema de Coordenadas Geográficas, Datum WGS84.

FONTE: Elaborada pela autora.

A pesca artesanal ocorre no domínio aquático do BELP e origina territórios populacionais próximos as suas margens, conhecidos como comunidades pesqueiras. Nas margens estão localizados os Planos Intermareais e as Praias estuarinas, que garantem simultaneamente às comunidades o serviço ecossistêmico denominado de "estrutura de suporte". Estes territórios são ocupados por moradias que acomodam pescadores e suas famílias e, também, por galpões onde são guardados e manejados petrechos, barcos e suprimentos para pesca. Outro benefício gerado pelos Planos Intermareais e Praias estuarinas, concomitante com os Baixios e Canais de drenagem (relacionados ao serviço de estrutura de suporte), é o espaço físico que estes ambientes oferecem para atracação das embarcações pesqueiras e para a construção de trapiches, viabilizando o desembarque da produção e a manutenção de equipamentos (beneficiando diretamente a infraestrutura do setor). Os serviços de regulação, balanço hídrico 
(e sedimentar) e diluição de efluentes também são fornecidos por estes ecossistemas. Estes processos beneficiam diretamente os moradores destas áreas ou próximos a estes locais, controlando possíveis alagamentos em suas moradias (benefício de segurança para ocupação adjacente e/ou manutenção da linha de costa), assegurando a qualidade da água para a pesca e atuando na recepção dos efluentes gerados pelos pescadores e pela atividade (Baixios, Planos Intermareais e Canais de drenagem).

No domínio aquático, a Zona Intermediária é o ecossistema predominante em termos de área, sendo o local preferencial para a pesca artesanal e o mais utilizado para a navegação de pequeno porte (Asmus et al., 2015). Os serviços gerados por este ecossistema- considerando a extensão desta região -, são: Suporte - O espaço oferecido para pesca (captura) e para navegação das embarcações pesqueiras, que viabiliza a logística do setor; e Regulação - O corpo d'água recebe efluentes gerados diretamente pela própria pesca e indiretamente pela comunidade pesqueira, beneficiando o sistema da pesca como um todo, por meio do seu potencial para diluição deste material. Os Baixios também fornecem o serviço definido como "espaço para pesca". Estas áreas são muito relevantes para a captura dos recursos (e não só como locais importantes de berçário e alimentação para o estoque) (Moura, 2009; Kalikoski \& Vasconcellos, 2006, 2013). A tainha Mugil adulta é uma das espécies dominantes capturada nestes ambientes (Vieira et al., 1998; Moura, 2009).

A tainha desova no ambiente marinho (oceano $)^{7}$ e utiliza os ecossistemas rasos do BELP como áreas de berçário e refúgio. Logo após o nascimento, os juvenis migram para região (ou ecossistema) costeira adjacente ao estuário - zona de arrebentação das praias arenosas do Cassino (Rio Grande) e do Mar Grosso (São José do Norte) - utilizando estas áreas como habitat intermediário especialmente para alimentação. Consequentemente, estes indivíduos são transportados pelas forçantes hidrodinâmicas ao longo desta área, as quais auxiliam seu deslocamento e agregação perto da boca estuarina e sua entrada neste ambiente (Vieira, 1991; Lemos et al., 2014). O canal de acesso ao BELP, estabilizado pelos molhes, é a via responsável pela conexão do ambiente estuarino com o ecossistema costeiro adjacente. Os molhes atuam na regulação da hidrodinâmica do canal e viabilizam o tráfego de grandes embarcações nesta região. A pesca artesanal se beneficia diretamente do serviço de suporte de "corredor ecológico" fornecido pelo ecossistema canal, que regula a entrada e a saída de água do estuário (em conjunto com os ventos e a precipitação) e possibilita a migração do estoque de tainha (entre outras espécies), que utiliza os ecossistemas estuarinos para alimentação e/ou reprodução. Os canais naturais também exercem um papel relevante nesse processo, fornecendo suporte para a migração final destes organismos até os ecossistemas rasos nas margens estuarinas.

O conjunto de ecossistemas rasos - Marismas, Vegetação Aquática Submersa (VAS), Planos Intermareais e Baixios - oferece funções e serviços fundamentais para o desenvolvimento do estoque pesqueiro, possibilitando, assim, a atividade de pesca artesanal (Tabela 1). Os serviços ecossistêmicos

${ }^{7}$ A desova do estoque sul de Mugil liza ocorre em condições ambientais específicas nas costas de Santa Catarina e Paraná (Lemos et al., 2014). 
gerados por este grupo de ambientes, que atuam beneficiando diretamente o estoque de tainha e, por conseguinte, todo o sistema da pesca, são as funções ecológicas (ou ecossistêmicas) a seguir: 1) Áreas que servem como local de berçário (larvas e juvenis) e de refúgio para os recursos; 2) Base que sustenta a produção de biodiversidade e a produtividade destas áreas, gerando incrementos na produção biológica e nos processos da rede trófica estuarina; 3) Ciclagem e exportação de nutrientes pelos organismos que reciclam a matéria orgânica, mantendo a qualidade da água e os processos de produção no estuário e ecossistemas adjacentes (Suporte); 4) Produção de biomassa vegetal, animal e detritos, garantindo alimento e nutrientes para os juvenis e adultos do estoque (Provisão).

\subsection{Modelos conceituais de fluxo energético}

Os modelos conceituais facilitam a análise do conjunto de componentes e interações da atividade pesqueira e possibilitam a identificação dos processos e controles mais relevantes para um melhor direcionamento nas ações de gestão com base nos ecossistemas, suas funções e serviços. Eles também podem servir como uma ferramenta para identificar espaços de planejamento (base de governança) e sua possível integração com as políticas públicas e os instrumentos de suporte. O primeiro, para o BELP, evidencia o funcionamento geral do estuário e o conjunto de componentes e processos que estão conectados para subsidiar o subsistema da pesca artesanal, e o segundo - com maior nível de detalhamento - apresenta os diferentes aspectos da atividade pesqueira e a produção (e geração) dos serviços ecossistêmicos que atuam diretamente na manutenção da pesca artesanal da tainha.

\subsubsection{Modelo do Baixo Estuário da Lagoa dos Patos (SISTEMA BELP)}

O Baixo Estuário da Lagoa dos Patos (BELP) pode ser descrito como um sistema complexo, integrado por componentes e processos (ecológicos e socioeconômicos) que se relacionam por meio de fluxos de energia e matéria. A pesca artesanal é uma atividade socioeconômica (configurada como um subsistema) que utiliza, interage e compete por espaço e serviços gerados pelos ecossistemas caracterizados (Seção 3.1). Para entender as conexões e interações da pesca artesanal com os ecossistemas identificados, e o uso dos habitats e o deslocamento feitos pelo estoque de tainha (Mugil liza) no ambiente estuarino, em um cenário mais amplo, foi confeccionado o modelo denominado SISTEMA BELP (Figura 3$)^{8}$. Os números que aparecem na figura e no texto correspondem aos processos e às funções que ocorrem no SISTEMA BELP e atuam na estrutura da pesca artesanal e no estoque de tainha.

No diagrama, apresentam-se em destaque os seguintes componentes: Ecossistemas Estuarinos, Ecossistemas Antropizados, Pesca e o Sistema (ecossistema) Costeiro Adjacente. Os ecossistemas

\footnotetext{
${ }^{8} \mathrm{O}$ limite definido para este estudo (ou a janela de observação - Odum, 1988) não isola o sistema em questão. O BELP está conectado a diferentes sistemas (dentro de um contexto ecológico e socioeconômico) e esta análise compreende, de modo específico, a modelagem conceitual da atividade de pesca artesanal, com ênfase na pesca da tainha, dentro do SISTEMA BELP, para a melhor compreensão dos fluxos energéticos ali presentes capazes de fornecer serviços ecossistêmicos.
} 
estuarinos produtores conectam-se por meio de um fluxo bidirecional com o estoque de tainha (Processos 8 e 9) e desempenham funções ecossistêmicas muito importantes, como a provisão de alimentos e a estrutura de suporte (habitat) para berçário e área de refúgio de juvenis e/ou adultos da espécie (8). Eles também fornecem suporte para infraestrutura e funcionamento dos ecossistemas antropizados (Processo 10). Estes, por sua vez, podem gerar impactos negativos pelas formas de uso e/ou ocupação dos ambientes naturais (Processo 11), porém, atuam de forma positiva na geração de serviços ecossistêmicos (Processo 18) para a Atividade de Pesca Artesanal da Tainha (Processo 12 - SISTEMA
PESCA). O ecossistema costeiro adjacente, assim como as fontes energéticas naturais (sol, vento, chuva e maré) e os controles institucionais (mercado e governo), encontra-se externo ao modelo. Este ambiente exerce um papel essencial na manutenção do ciclo de vida da tainha (Processo 7) e no sustento de alguns fluxos energéticos dentro do BELP e no SISTEMA PESCA, participando da dinâmica de importantes funções e serviços gerados.

A maior parte dos ecossistemas naturais (Marismas, Vegetação Aquática Submersa (VAS), Planos Intermareais, Baixios e Zona Intermediária) constitui o componente produtor do SISTEMA BELP. Estes ambientes são altamente produtivos,

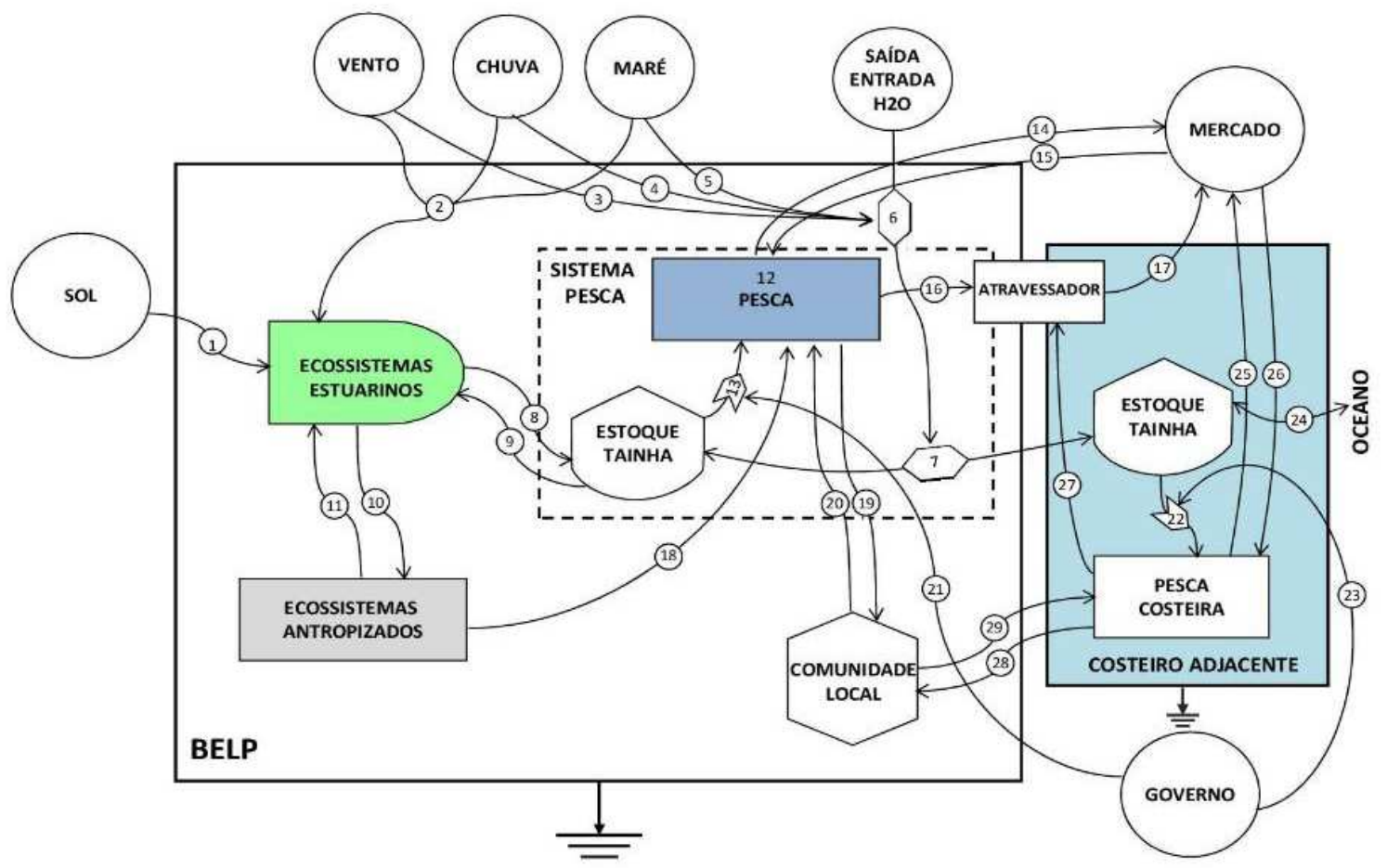

FIGURA 3 - Modelo conceitual representando os principais componentes e processos mapeados no sistema do Baixo Estuário da Lagoa dos Patos (SISTEMA BELP).

FONTE: Produzido pela autora. 
ricos em material orgânico de origens vegetal e animal e integram diversos processos ecológicos envolvidos na produção de biomassa estuarina (ex.: produção e produtividade primária (bruta e líquida), secundária, sistema decompositor - Odum (1972; 1988). No diagrama, o processo 1 representa a produção biológica (função ecossistêmica) gerada pelos ecossistemas produtores a partir da fonte de energia solar.

Os produtores (fitoplâncton, VAS, vegetação das marismas) captam, transformam a energia emitida pelo sol (fotossíntese) e a transferem para o componente consumidor (neste caso, o estoque de tainha) via cadeia trófica (zooplâncton, bentos) (processo 8). Em contrapartida, os consumidores eliminam parte dessa energia por meio de dejetos e uma quantidade de matéria orgânica e detrito retorna para o ecossistema estuarino, ficando disponível para os produtores sob forma inorgânica pela ação dos decompositores (Processo 9). A energia proveniente das outras forçantes naturais externas, como o vento, a chuva e a maré, também age diretamente sobre os ecossistemas produtores (entre outros), sendo direcionada e transformada para sua utilização pelos componentes consumidores (Processo 2). Estas variáveis atuam por meio da coluna d'água influenciando a circulação estuarina e o fluxo de entrada e saída de água no sistema (Processos 3, 4, 5 e 6), controlando assim, também, o fluxo bidirecional do estoque de tainha entre o BELP e o ecossistema costeiro adjacente (Processo 7).

A tainha desova no ambiente marinho (oceano) e utiliza os ecossistemas rasos do BELP como áreas de berçário e refúgio. Após a migração costeira para reprodução e desova no ambiente marinho (Processo 24), os juvenis da espécie retornam para utilizar os ecossistemas estuarinos do BELP como área de refúgio (berçário) e alimentação. A captura pela frota artesanal ocorre o ano todo na porção estuarina (Processo 13) e nas águas costeiras adjacentes (Processo 22), seguindo o padrão de uso dos habitats pelos indivíduos em diferentes estágios do seu ciclo de vida (Kalikoski \& Vasconcellos, 2013). O controle da atividade é feito pelas políticas governamentais que regulam a retirada do estoque (Processos 21 e 23), operando por meio da legislação vigente e da fiscalização pelas instituições responsáveis (MMA, MAPA, MDIC, IBAMA, Fórum da Lagoa dos Patos). A comercialização do pescado na região se dá de maneiras distintas (Garcez \& Sanchez-Botero, 2005). Em síntese, as cadeias produtivas estão ligadas aos atravessadores que compram o peixe diretamente dos pescadores (Processos 16 e 27) e revendem a outros atravessadores que revendem para as indústrias ou para os consumidores (Processo 17). Nos resultados do censo publicado por Kalikoski \& Vasconcellos (2013), uma porcentagem de pescadores $-17,2 \%$ em Rio Grande e 3,5\% em São José do Norte declara que a venda de uma parte da produção é feita diretamente ao consumidor final (Processos 14 e 25). Outra parte garante a segurança alimentar da comunidade local (Processo 28) que, em troca, fornece mão de obra, material, infraestrutura, etc. para o setor pesqueiro (Processo 29). Do mercado (consumidor e fornecedor), o pescador (SISTEMA PESCA) recebe os insumos pelo pescado e também adquire bens e serviços que facilitam o exercício da pesca, como o combustível, os equipamentos, a assistência para reparos e manutenção, a documentação e a alimentação (Processos 15 e 26). 


\subsubsection{Modelo Pesca Artesanal da tainha (SISTEMA PESCA)}

A pesca artesanal da tainha no BELP depende de uma série de ecossistemas e processos (funções e serviços ecossistêmicos) que oferecem suporte para diferentes aspectos do setor. Para compreender melhor as características deste sistema e a produção (e o uso) dos serviços ecossistêmicos, que atuam diretamente na sua manutenção, foi elaborado um segundo modelo conceitual diagramático (SISTE-
MA PESCA) (Figura 4), onde a escala da janela de observação foi ajustada para um nível maior de detalhamento da atividade pesqueira.

O diagrama SISTEMA PESCA oferece uma leitura sinóptica dos componentes e processos dominantes da matriz de ecossistemas, serviços, benefícios e atores beneficiários que compõem a base ecossistêmica da pesca artesanal no BELP. Ele exibe todos os ecossistemas, incluindo os resultantes de atividades antrópicas, como componentes fundamentais que estimulam ou controlam

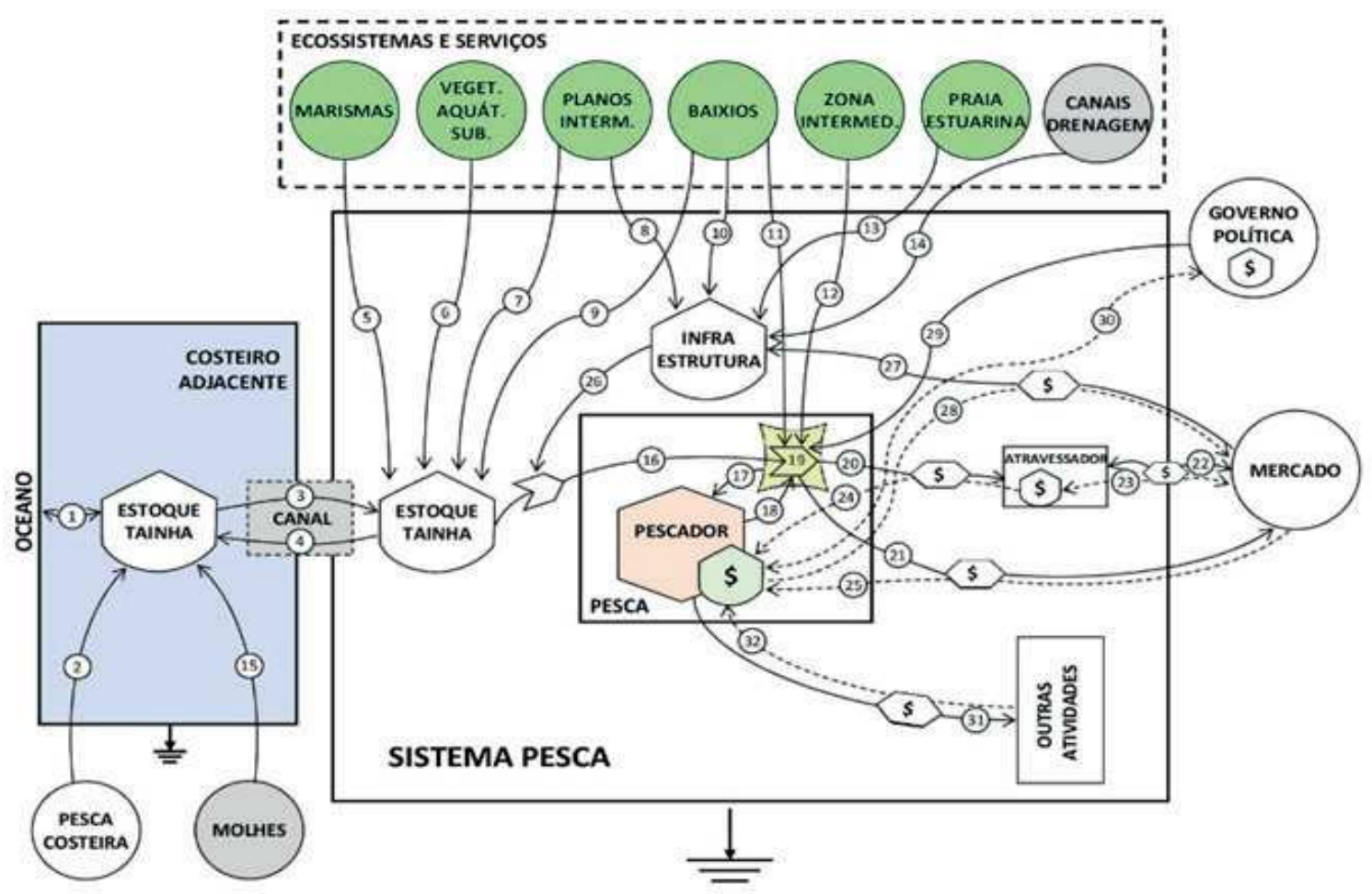

FIGURA 4 - Modelo conceitual representando os principais componentes e processos mapeados no sistema da Pesca Artesanal da Tainha no BELP (SISTEMA PESCA).

FONTE: Produzido pela autora. 
o fornecimento de funções e serviços, subsidiando o estoque e todo o sistema da pesca artesanal da tainha e ilustrando as principais conexões energéticas (fluxos) decorrentes de um ou mais processos (ecológicos e/ou socioeconômicos) dominantes. Em síntese, o SISTEMA PESCA apresenta em sua estrutura central: I) o Estoque de Tainha; II) a Infraestrutura; III) o Subsistema Pesca (pescador, estoque financeiro, símbolo do interruptor); IV) o Atravessador; V) o Mercado (consumidor e fornecedor); e VI) o Governo (política governamental). Assim como o BELP, estabelece uma série de relações de dependência com os outros sistemas (ou subsistemas) externos - como o subsistema Ecossistemas estuarinos e Serviços e o Sistema (ecossistema) Costeiro Adjacente - e internos, como o subsistema PESCA, relacionando-se também, com os principais controles institucionais externos - mercado e governo.

O conjunto de Ecossistemas estuarinos e Serviços, delimitado por uma linha tracejada, atua como o principal controle dos componentes e como fonte de funções e serviços ecossistêmicos significativos que viabilizam o funcionamento de todo o SISTEMA PESCA e do subsistema PESCA (Processos $5,6,7,8,9,10,11,12,13$ e 14). O subsistema PESCA (destacado no interior do modelo) apresenta o elemento Pescador, que representa a base social da pesca artesanal no BELP, incluindo os espaços de organização existentes, como as colônias e os sindicatos; o símbolo de estoque financeiro, que configura as interações econômicas e a remuneração pela atividade; e também o símbolo do interruptor (ou gatilho) (Processo 19), que é definido como a ação da pesca propriamente dita, em razão de ser a estrutura responsável por conectar uma série de interações e processos (fluxos energéticos) relevan- tes estabelecidos pela pesca com os ecossistemas, com o estoque, com o governo e com o mercado. $\mathrm{O}$ sistema costeiro adjacente conecta-se com o SISTEMA PESCA por meio dos ecossistemas localizados na interface entre o BELP e o ambiente marinho. Estes ecossistemas - canal fixado pelos molhes e canais naturais - facilitam as interações físicas e biológicas estuarinas e garantem o intercâmbio do estoque de tainha (Processos 3 e 4 ) e de outras espécies que dependem do estuário para completar seu ciclo de vida. Desta forma, a atividade de pesca em si é favorecida, ou seja, a captura do recurso pelo pescador acontece (Processo 16), especialmente devido aos serviços de suporte gerados por estes ecossistemas, que atuam como um "corredor ecológico", assegurando o processo de migração dos peixes. Outros controles importantes para o sistema em questão são os mercados consumidor e fornecedor (mercado) e a política governamental (governo-política). O mercado recebe a produção pesqueira via pescador (Processo 21) ou atravessador (Processo 22) e fornece material e insumos (bens e serviços), como combustível, equipamentos, assistência, documentação e alimentação para o subsistema PESCA (pescador), favorecendo a prática da atividade (Processos 25 e 27); e o governo atua na regulamentação da atividade (do estoque) por meio das políticas de controle, crédito, licenciamento e fiscalização pelas instituições responsáveis (MMA, IBAMA, Fórum da Lagoa dos Patos) (Processos 29 e 30).

\section{Considerações finais}

Os resultados obtidos ao longo desta pesquisa demonstram a importância dos ecossistemas identi- 
ficados na geração de serviços essenciais para a manutenção dos diferentes componentes da atividade de pesca artesanal da tainha no BELP e permitem que sejam tomados como base de informação para futuros estudos científicos e para iniciativas de planejamento e gestão (público-privada) da atividade pesqueira.

No contexto do BELP, a pesca artesanal é uma atividade socioeconômica muito importante, que garante alimentação e renda (benefícios) para muitas comunidades. Diante da atual situação de crise, as estratégias de planejamento e gestão exigem atenção e eficácia, uma vez que suas interações são bastante complexas e diferentes em cada ecossistema, compartilhando diversos serviços com os demais setores econômicos da região (porto, indústria, turismo, etc.). Nesta perspectiva, o enfoque ecossistêmico se apresenta como uma abordagem capaz de dar suporte a uma gestão adequada da pesca artesanal da tainha, visto que, no Brasil (e neste caso no BELP), a gestão da atividade pesqueira - independente da sua modalidade - se estabeleceu com foco no recurso pesqueiro, sem considerar a importância do ambiente em que todo o sistema da pesca está inserido. As áreas estuarinas, assim como os ecossistemas do BELP identificados nesta pesquisa, são definidos pelo Plano Nacional de Gerenciamento Costeiro - GERCO ${ }^{9}$ - como de alta prioridade para a gestão, por conta do seu elevado nível de risco ambiental e impactos atuais (Zamboni \& Nicolodi, 2008). Embora a atividade de pesca forneça recursos costeiros importantes, o GERCO não tem jurisdição sobre eles. A atividade encontra-se dissociada das políticas de gerencia- mento costeiro integrado, mesmo fazendo uso dos ecossistemas e de seus serviços.

O conceito de Gerenciamento Costeiro Integrado surgiu algumas décadas após o estabelecimento dos modelos de gestão pesqueira sob um enfoque muito distinto. O GCI teve seu início nos anos 1970 e passou a consolidar-se como prática internacionalmente aceita apenas na década de 1990, por meio de modelos que contemplavam o desenvolvimento sustentável e a resolução de conflitos por espaços e recursos naturais (Milton Asmus, obs. pess.). É provável que as diferenças de contextos e os enfoques inerentes às épocas distintas tenham influenciado as práticas adotadas pelas ações de gestão. Em outras palavras, pode-se afirmar que houve uma discrepância histórica entre a gestão pesqueira e o GCI que consolidou escolas acadêmicas e administrativas igualmente discrepantes entre si. Com isso, temos a pesca ordenada por órgãos e leis específicas, enquanto que os espaços costeiros (ecossistemas) são gerenciados por outros procedimentos e instrumentos do GCI.

No estuário da Lagoa dos Patos, a pesca artesanal é regulamentada pela Instrução Normativa Conjunta MMA/SEAP n ${ }^{\circ} 03$, de 09 de fevereiro de 2004 (IN N ${ }^{\circ}$. 03/2004). Este documento pode ser considerado uma referência sobre a forma como a gestão pesqueira é planejada no território nacional, onde estabelece restrições e recomendações voltadas aos modos de pesca (petrechos, embarcações, limites de tamanho e de esforço de pesca), bem como aos períodos temporais da atividade (emissão de licença, defeso, etc.). Ele, porém, não prioriza os ambientes que subsidiam a atividade pesqueira. A

\footnotetext{
${ }^{9}$ Esta política estabelece (define) aspectos legais e bases para o desenvolvimento de programas e planos de manejo regionais e locais acerca da utilização dos recursos naturais, visando ao ordenamento da ocupação dos espaços litorâneos.
} 
gestão e a proteção dos habitats - que são importantes para pescarias no BELP - são definidas por uma legislação própria ${ }^{10}$, regulamentada por agências ambientais estaduais e federais que estabelecem alguns padrões para qualidade hídrica e regulam os tipos de uso dos sistemas estuarinos e dulcícolas, protegendo habitats críticos, como banhados e ecossistemas ripários (Kalikoski \& Vasconcellos, 2013). Ambos os regramentos atuam apenas em seus respectivos escopos e não contemplam a proteção de habitats marinhos, próximos ou afastados da costa.

A base de informações gerada sobre a atividade pesqueira e os ecossistemas (e seus diferentes aspectos) cumpre com o roteiro proposto (road map) por Asmus (2016) $)^{11}$ para subsidiar uma iniciativa de gestão com base ecossistêmica, onde foram/foi: 1) caracterizados os ecossistemas como unidades de gestão; 2) mapeados e modelados os principais sistemas - ou ecossistemas - para obtenção de uma visão integrada dos seus principais componentes (ecológicos, econômicos e sociais); 3) identificados os principais serviços ecossistêmicos - e suas possíveis ameaças (risco de perdas); 4) definida a qualidade dos ecossistemas e serviços por meio de uma percepção social (entrevistas com os pescadores artesanais $)^{12}$. A matriz das informações estabelece uma base de dados que permite visualizar a conexão da atividade pesqueira com os ecossistemas identificados e reconhecer o uso que este setor faz nestes ambientes e a maneira como utiliza os serviços ecossistêmicos em favor do seu bem-estar (benefícios e atores beneficiados). A metodologia ${ }^{13}$ que gerou esta matriz pode ser reaplicada para elaborar outros trabalhos, adaptando a sequência "ecossistemas, serviços, benefícios e beneficiários" de acordo com os interesses científicos ou de gestão. Por exemplo, em circunstâncias onde a pesca artesanal pode ser substituída por outra atividade (ou uso) socioeconômico da zona costeira e, também, para outros estudos que caracterizem sistemas costeiros complexos (Scherer \& Asmus, 2016) ou que atuem junto à base de governança, como proposto por Asmus (2016). Os modelos facilitam a análise dos principais processos de influência, interações e controles (ambientais, sociais e institucionais) da atividade pesqueira artesanal (e seus diferentes componentes), servindo como uma ferramenta para identificar futuros espaços de gestão e planejamento (base de governança) e também sua possível integração com as políticas públicas e os instrumentos de suporte.

Este estudo de caso apresentou uma perspectiva de como ocorrem as diferentes relações entre a pesca artesanal (tainha) e os ecossistemas

\footnotetext{
${ }^{10}$ Neste contexto, alguns exemplos são a Política Nacional do Meio Ambiente (PNMA), compreendida no âmbito do Ministério do Meio Ambiente (MMA); a Lei de Crimes Ambientais, que determina as sanções penais para os crimes contra fauna e flora e que instituiu o Sistema Nacional de Unidades de Conservação da Natureza (SNUC) e o Plano Nacional do Gerenciamento Costeiro (PNGC), que faz o zoneamento de usos e atividades na zona costeira, dando prioridade à conservação e à proteção.

${ }^{11}$ Palestra proferida no II Congresso Ibero-Americano sobre Gestão Integrada de Áreas Litorais. Florianópolis, Brasil, maio de 2016.

${ }^{12} \mathrm{Na}$ dissertação que deu origem a este artigo, Costa (2017) realizou entrevistas semiestruturadas em comunidades pesqueiras dos dois municípios no entorno do BELP (Rio Grande e São José do Norte) com o objetivo de identificar a relação dos pescadores artesanais com os ecossistemas e os serviços por eles gerados. Os relatos dos entrevistados comprovam que muitos dos saberes ditos populares corroboram o que é encontrado na literatura científica. Neste sentido, pode-se perceber que o conhecimento tradicional também pode fornecer importantes contribuições aos trabalhos científicos e também subsidiar políticas públicas (por meio de processos participativos).

${ }^{13}$ Conhecimento especializado (Krueger et al., 2012; Nordlund et al., 2016).
} 
do BELP. E mostra que podemos, a partir de uma visão sistêmica integrada - diferente do que tem sido realizado -, planejar um modelo de gestão (independentemente de o setor responsável ser um órgão público ${ }^{14} \mathrm{e} / \mathrm{ou}$ privado) focado nos diferentes componentes (conforme os modelos apresentados neste trabalho) e nos principais processos e controles ecológicos (ecossistemas), socioeconômicos (atividade pesqueira) e institucionais (mercado e governança), onde se reconhecem os efeitos (negativos e/ou positivos) resultantes das perdas de serviços ecossistêmicos e, consequentemente, dos benefícios para os pescadores e outros atores da cadeia produtiva. A pesquisa trouxe alguns indícios necessários (e possíveis) para realizarmos novas mudanças na mentalidade, na legislação e nos meios de fazer a gestão deste setor. Tanto a ciência quanto os gestores públicos procuram soluções eficientes para garantir a sustentabilidade ambiental e social, porém, os meios para que isso ocorra continuam sendo controversos e setorizados. O sistema da pesca artesanal da tainha no BELP - assim como poderia ter sido outra atividade nos ambientes costeiros - foi o exemplo utilizado para demonstrar como é possível estabelecer uma base de informações integradas para gestão com base ecossistêmica, além de oferecer possibilidades para outros debates e experiências dentro deste mesmo contexto.

\section{Agradecimentos}

Aos pescadores artesanais do Baixo Estuário da Lagoa dos Patos.
A todos os colaboradores do grupo de gestão com base ecossistêmica do Laboratório de Gerenciamento Costeiro (LABGERCO) do Instituto de Oceanografia da Universidade Federal do Rio Grande (FURG), pelas discussões produtivas e trocas de conhecimento. Ao Programa de Pós-Graduação em Gerenciamento Costeiro e à CAPES como fonte financiadora da pesquisa, por meio da bolsa de mestrado.

\section{Referências}

Abdallah, P. R.; Sumaila, U. R. An historical account of Brazilian public policy on fisheries subsidies. Marine Policy, 31(4), 444-450, 2007.

Agardy, T. Effects of fisheries on marine ecosystems: a conservationist's perspective. ICES Journal of Marine Science: Journal du Conseil, 57(3), 761-765, 2000.

Arkema, K. K.; Abramson, S. C.; Dewsbury, B. M. Marine ecosystem-based management: from characterization to implementation. Frontiers in Ecology and the Environment, 4(10), 525-532, 2006.

Asmus, M. L. A planície costeira e a Lagoa dos Patos. In: Seeliger, U.; Odebrecht, C.; Castello J. P. (Eds.). Os ecossistemas marinho e costeiro do extremo sul do Brasil. Rio Grande: Editora Ecoscientia, 1998. Cap. 3, p. 9-12.

Asmus, M. L; Nicolodi, J.L; Anello, L.S.; Gianuca, K. Planilha de Ecossistemas e Serviços para o Baixo Estuário da Lagoa dos Patos (BELP). In: Conde, D.; Polette, M.; Asmus, M. Risk, perception and vulnerability to Climate Change in wetland dependent coastal communities in the Southern Cone of Latin America. Final Report. IDRC Climate Change and Water program Project 6923001, 2015.

Asmus, M. L. Gestão com Base Ecossistêmica (GBE) de Sistemas Marinhos e Costeiros. Anais do II Congresso

\footnotetext{
${ }^{14}$ Uma das características da gestão integrada é incorporar este modelo em diferentes níveis governamentais. Os órgãos que deverão atuar nestes processos estão inseridos nas esferas municipais, estaduais e federais. Em uma atividade como a pesca artesanal, isto se torna necessário. (Milton Asmus, obs. pess.).
} 
Ibero-Americano sobre Gestão Integrada de Areas Litorais, Florianópolis, SC, Brasil, 2016.

Azevedo, N. T. de; Pierri, N. A política pesqueira no Brasil (2003-2011): a escolha pelo crescimento produtivo e o lugar da pesca artesanal. Desenvolvimento e Meio Ambiente, 32, 61-80, 2014.

Barbosa, F. G.; Wallner-Kersanach, M.; Baumgarten, M. G. Z. Metais traço nas águas portuárias do estuário da Lagoa dos Patos, RS. Brazilian Journal of Aquatic Science and Technology, 16(2), 27-36, 2012.

Béné, C.; Hersoug, B.; E. H. Allison. "Not by rent alone": analysing the propoor functions of small-scale fisheries in developing countries. Development Policy Review, 28, 325-358, 2010.

Berkes, F. From community-based resource management to complex systems. Ecology and Society, 11(45), 2006. [on-line] Disponível em: <http://www.ecologyandsociety. org/vol11/iss1/art45/>

Castello, J. P. O futuro da pesca e da aquicultura marinha no Brasil: A pesca costeira - Ciências do Mar/Artigos. Ciência e Cultura, 62(3): 32-35, 2010.

Copertino, M. S.; Creed, J. C.; Lanari, M. O.; Magalhães, K.; Barros, K.; Lana, P. C.; Sordo, L.; Horta, P. A. Seagrass and Submerged Aquatic Vegetation (VAS) Habitats off the Coast of Brazil: state of knowledge, conservation and main threats. Brazilian Journal of Oceanography, 64(n.spe2), 53-80, 2016.

Costa, J. C. Base Ecossistêmica da atividade pesqueira artesanal: estudo de caso no Baixo Estuário da Lagoa dos Patos (BELP), RS, Brasil. 154 p. Rio Grande, Dissertação (Mestrado em Gerenciamento Costeiro) - FURG, 2017.

De Groot, R. S. Functions of Nature: Evaluation of Nature in Environmental Planning, Management and Decision Making. Groningen: Wolters-Noordhoff, 1992.

De Groot, R.; Wilson, M. A.; Boumans, R. M. J. A typology for the classification, description and valuation of ecosystem functions, goods and services. Ecological Economics, 41, 393-408, 2002.

FAO. Artisanal Fisheries. FAO Glossary, 2012. Disponível em: $<$ http://www.fao.org/glossary/>. Food and Agriculture
Organization. Acesso em: 12 fev. 2017.

FAO. The state of world fisheries and aquaculture 2014. FAO Fisheries and Aquaculture Department. Roma: FAO, 2014. 233 p.

FAO. Enfoque ecosistémico pesquero: Conceptos fundamentales y su aplicación en pesqueras de pequeña escala de América Latina, por Omar Defeo. FAO Documento Técnico de Pesca y Acuicultura No. 592. Roma, Italia, 2015.

Ferreira, C. N. Caracterização da pesca e abundância relativa da Tainha (Mugil platanus) (Gunther, 1880) no estuário da Lagoa dos Patos. 147 p. Rio Grande, Dissertação (Mestrado em Oceanografia Biológica) - Instituto de Oceanografia, Universidade Federal do Rio Grande, FURG, 2007.

Freitas, D. M.; Tagliani, P. R. A. The use of GIS for the integration of traditional and scientific knowledge in supporting artisanal fisheries management in southern Brazil. Journal of Environmental Management, 90(6), 2071-2080, 2009.

Garcez, D. S.; Sanchez-Botero, J. I. Comunidades de pescadores artesanais no Estado do Rio Grande do Sul, Brasil. Atlântica, 27, 17-29, 2005.

Garcia, A. M.; Vieira, J. P.; Winemiller, K. O. Dynamics of shallow-water fish assemblage of the Patos Lagoon estuary (Brazil) during cold and warm ENSO episodes. Journal of Fish Biology, 59, 1218-1238, 2001.

Haimovici, M.; Andrigueto, J. M.; Sunye, P. S. Diagnóstico da pesca no litoral do Rio Grande do Sul. In: Isaac, V. J.; Martins, A. S.; Haimovici, M.; Andrigueto, J. M. A pesca marinha e estuarina do Brasil no início do século XXI: recursos, tecnologias, aspectos socioeconômicos e institucionais. Projeto RECOS: Uso e apropriação dos recursos costeiros. Grupo Temático: Modelo Gerencial da pesca. Belém: UFPA, 2006. p. 157-180.

Halpern, B. S.; Walbridge, S.; Selkoe, K. A.; Kappel, C. V.; Micheli, F.; D’Agrosa, C.; Bruno, J. F.; Casey, K. S.; Ebert, C.; Fox, H. E.; Fujita, R.; Heinemann, D.; Lenihan, H. S.; Madin, E. M. P.; Perry, M. T.; Selig, E. R.; Spalding, M.; Steneck, R.; Watson, R. A global map of human impact on marine ecosystems. Science, 319(5865), 948-952, 2008.

Hellebrandt, L. M. Conflitos da pesca artesanal de tainha na colônia Z3 e sua relação com as políticas públicas. 102 
p. Rio Grande, Dissertação (Mestrado em Gerenciamento Costeiro) - Instituto de Oceanografia, Universidade Federal do Rio Grande, FURG, 2012.

Kaiser, M. J.; Collie, J. S.; Hall, S. J.; Jennings, S.; Poiner, I. R. 12 Impacts of Fishing Gear on Marine Benthic Habitats. Responsible Fisheries in The Marine Ecosystem, 57(3), 197, 2003.

Kalikoski, D. C.; Rocha, R. D.; Vasconcellos, M. C. Importância do conhecimento ecológico tradicional na gestão da pesca artesanal no estuário da Lagoa dos Patos, extremo sul do Brasil. Ambiente \& Educação, 11, 87-118, 2006.

Kalikoski, D. C.; Vasconcellos, M. Estudo das condições técnicas, econômicas e ambientais da pesca de pequena escala no estuário da Lagoa dos Patos, Brasil: uma metodologia de avaliação. FAO Fisheries and Aquaculture, Circular n. 1075. Rome: FAO, 2013. 227 p.

Kolding, J.; Béné, C.; Bavinck, M. Small-scale fisheries-importance, vulnerability, and deficient knowledge. In: Garcia, S.; Rice, J.; Charles, A. (Eds.). Governance of marine fisheries and biodiversity conservation. UK: John Wiley \& Sons, Ltd., 2014.

Krueger, T.; Page, T.; Hubacek, K; Smith, L; Hiscock, K. The role of expert opinion in environmental modelling. Environmental Modelling \& Software, 36, 4-18, 2012.

Lemos, V. M.; Varela, A. S.; Schwingel, P. R.; Muelbert, J. H.; Vieira, J. P. Migration and reproductive biology of Mugil liza (Teleostei: Mugilidae) in South Brazil. Journal of Fish Biology, 85(3), 671-687, 2014.

Leslie, H. M.; McLeod, K. L. Confronting the challenges of implementing marine ecosystem-based management. Frontiers in Ecology and the Environment, 5(10), 540-548, 2007.

Leslie, H. M.; Kinzig, A. P. Resilience Science. In: McLeod, K. L.; Leslie, H. (Eds.). Ecosystem-based management for the oceans. Washington: Island Press, 2009. p. 55-73.

Link, J. S. Ecosystem-Based Fisheries Management: Confronting Tradeoffs. Cambridge, UK: Cambridge University Press, 2010.

Link, J. S.; Browman, H. I. Integrating what? Levels of marine ecosystem-based assessment and management. ICES Journal of Marine Science, 71: p.1170-1173, 2014.
Marangoni, J. C.; Costa, C. S. B. Caracterização das atividades econômicas tradicionais no entorno das marismas no estuário da Lagoa dos Patos (RS). Desenvolvimento e Meio Ambiente, 21, 129-142, 2010.

MEA. Millenium Ecosystem Assessment. Ecosystems and Human Well-being: Synthesis. Washington: Island Press, 2005. Disponível em: <http://www.millenniumassessment. org/en/Synt hesis.html>. Acesso em: jan. 2017.

Minayo, M. C. S. Ciência, técnica e arte: o desafio da pesquisa social. In: Minayo, M. C. S (Org.). Pesquisa social: teoria, método e criatividade. Petrópolis, RJ: Vozes, p.09-29, 2001.

Misund, O. A.; Kolding, J.; Fréon, P. Fish capture devices in industrial and artisanal fisheries and their influence on management. Handbook of Fish Biology and Fisheries, 2, 13-36, 2002.

Moura, G. G. M. Águas da Coréia: pescadores, espaço e tempo na construção de um território de pesca na Lagoa dos Patos (RS) numa perspectiva etnooceanográfica. Programa de Pós-Graduação em Ciência Ambiental. São Paulo: Universidade de São Paulo, 2009.

MPA/FURG. Projeto Estatísticas de Desembarque Pesqueiro RS, 2010. Disponível em: $<$ http://www.imef.furg. br/index.php/servidores/docentes/matem/1095-estatistica-pesqueira-kinas.html>. Acesso em: ago 2017.

MPA/MMA. Plano de gestão para o uso sustentável da tainha, Mugil liza Valenciennes, 1836, no Sudeste e Sul do Brasil. Brasília, 2015. 137 p.

Nordlund, L. M.; Koch, E. W.; Barbier, E. B.; Creed, J. C. Seagrass Ecosystem Services and Their Variability across Genera and Geographical Regions. PloS one, 11(10), e0163091, 2016.

Nyland, J. A. R. Usos e conflitos nas margens e no domínio aquático no baixo estuário da Lagoa dos Patos, RS. 74 p. Rio Grande, Trabalho de conclusão de curso (Graduação em Oceanologia) - Instituto de Oceanografia, Universidade Federal do Rio Grande, FURG, 2015.

Odum, H. T. An Energy Circuit Language for Ecological and Social Systems: Its Physical Basis. In: Patten, B. C. (Ed.). Systems Analysis and Simulation in Ecology. New 
York: Academic Press, 1972. p. 140-212.

Odum, H. T. Systems Ecology. New York: Willey Interscience, 1983. $644 \mathrm{p}$.

Odum, H. T. Fundamentos de Ecologia. 4 ed. Lisboa: Fundação Calouste Gulbekian, 1988. 927 p.

Pasquotto, V. F. Pesca artesanal no Rio Grande do Sul: os pescadores de São Lourenço do Sul e suas estratégias de reprodução social. 164 f. Porto Alegre, Dissertação (Mestrado em Desenvolvimento Rural) - Faculdade de Ciências Econômicas, Universidade Federal do Rio Grande do Sul, 2005.

Pikitch, E.; Santora, C.; Babcock, E. A.; Bakun, A.; Bonfil, R.; Conover, D. O.; Dayton, P.; Doukakis, P.; Fluharty, B.; Heneman, E. D.; Houde, J.; Link, P. A.; Livingston, M.; Mangel, M. K.; McAllister, J.; Pope; Sainsbury, J. K. Ecosystem-based fishery management. Science, 305(5682), 346-347, 2004.

Reis, E. G.; D'Incao, F. The present status of artisanal fisheries of extreme southern Brazil: an effort towards community-based management. Ocean \& Coastal Management, 43(7), 18, 2000.

Santos-Martín, F.; Montes, C.; Alcorlo, P.; García-Tiscar, S.; González, B.; Vidal-Abarca, M. R.; Suárez, M. L.; Royo, L.; Férriz, I.; Barragán, J. M.; Chica, A.; López, C.; Benayas, J. De la gestión de los recursos pesqueros a la gestión de los ecosistemas: La aproximación de los servicios de los ecosistemas aplicada a la gestión pesquera. Ambienta, 1(111), 74-87, 2015.

Schafer, A. G.; Reis, E. G. Artisanal fishing areas and traditional ecological knowledge: The case study of the artis+anal fisheries of the Patos Lagoon estuary (Brazil). Marine Policy, 32(3), 283-292, 2008.

Scherer, M. E. G.; Asmus, M. L. Ecosystem-Based Knowledge and Management as a tool for Integrated Coastal and Ocean Management: A Brazilian Initiative. In: Vila-Concejo, A.; Bruce, E.; Kennedy, D. M.; McCarroll, R. J. (Eds.). Proceedings of the 14th International Coastal Symposium (Sydney, Australia). Journal of Coastal Research, Special Issue, 75, Coconut Creek (Florida), ISSN 0749-0208, 2016.

Seeliger, U.; Costa, C. S. B. Lições ecológicas e futuras tendências. In: Seeliger, U.; Odebrecht, C. (Org.). O estuário da Lagoa dos Patos: um século de transformações. Rio Grande/RS: Editora FURG, 2010. p. 147-152.

Tagliani, P. R. A.; Asmus, M. L. O Programa de Manejo Integrado do Estuário da Lagoa dos Patos. In: Tagliani, P. R.; Asmus, M. (Ed.). Manejo Integrado do Estuário da Lagoa dos Patos: uma experiência de gerenciamento costeiro no sul do Brasil. Rio Grande: Editora da FURG, 2011. 252 p., p. 27-39.

Vasconcellos, M.; Diegues, A. C.; Salles, R. R. Limites e gestão da pesca artesanal costeira. In: Costa, A. L. (Ed.). Nas redes da pesca artesanal. Brasília: PNUD/IBAMA, 2007. p. 15-83.

Vieira, J. P. Juvenile mullets (Pisces: Mugilidae) in the Estuary of Lagoa dos Patos, RS, Brazil. Copeia, 409-418, 1991.

Vieira, J. P.; Castello, J. P.; Pereira, L. E.; Seeliger, U.; Odebrecht, C.; Castello, J. P. Ictiofauna. In: Seeliger, U.; Odebrecht, C.; Castello J. P. (Eds.). Os ecossistemas marinho e costeiro do extremo sul do Brasil. Rio Grande: Editora Ecoscientia, 1998. Cap 4.13, p. 60-67.

Vieira, J. P.; Garcia, A. M.; Grimm, A. M. Evidences of El Niño effects on the mullet fishery of the Patos Lagoon Estuary. Brazilian Archives of Biology and Technology, 51, 433-440, 2008.

Worm, B.; Barbier E. B.; Beaumont N.; Emmett J. D.; Folke, C.; Halpern, B. S.; Jackson, J. B. C.; Lotze, H. K.; Micheli, F.; Palumbi, S. R.; Sala, E.; Selkoe, K. A.; Stachowicz, J. J.; Watson, R. Impacts of biodiversity loss on ocean ecosystem services. Science, 314(5800), 787-790, 2006.

Zamboni, A.; Nicolodi, J. L. (Org.). Macrodiagnóstico da Zona Costeira e Marinha do Brasil. 242 p. Ministério do Meio Ambiente (MMA), Secretaria de Mudanças Climáticas e Qualidade Ambiental, Brasília, DF, Brasil. ISBN 978-8577381128, 2008. Disponível em: <http://www.mma. gov.br/component $/ \mathrm{k} 2 / \mathrm{item} / 7562$ ? Itemid=866 $>$. Acesso em: jan 2017. 